\title{
19
}

\section{Schmetterlinge (Mittelworträtsel)}

Suche in jeder Zeile das Wort, welches man links anfügen und rechts voransetzen kann, zum

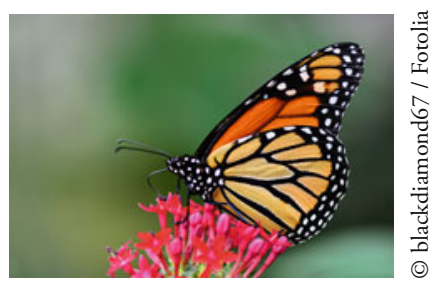
Beispiel SONNEN - SEGEL - FALTER (s. u.). Die Buchstaben in den neun vorgegebenen Boxen ergeben - von oben nach unten gelesen - das Lösungswort.

Tipp In jeder Zeile findet sich eine Schmetterlingsart.

\begin{tabular}{cll} 
MUTTER & \multicolumn{1}{c}{ PFAUENAUGE } \\
\hline KAISER & FLÄCHE \\
\hline STAATS & MANTEL \\
\hline SCHACH & SPIEL \\
\hline GRIECHEN & $-\square$ & KÄRTCHEN \\
\hline SONNEN & FALTER \\
\hline KLEINER & BANDWURM \\
\hline SILBER & $-\square-\square$ & FALTER \\
\hline TRIEB & GEISTCHEN \\
\hline ROSEN & WEIßLING
\end{tabular}

Lösung:

(C) Springer-Verlag Berlin Heidelberg 2016

C. Reinbold, Fetthenne, Moderlieschen, Warzenbeißer,

DOI 10.1007/978-3-662-52817-4_19 